\title{
Micrometeorological processes driving snow ablation in an Alpine catchment
}

\author{
R. Mott ${ }^{1}$, L. Egli ${ }^{1}$, T. Grünewald ${ }^{1,2}$, N. Dawes ${ }^{1}$, C. Manes ${ }^{3}$, M. Bavay ${ }^{1}$, and M. Lehning ${ }^{1,2}$ \\ ${ }^{1}$ WSL Institute for Snow and Avalanche Research SLF, Davos, Switzerland \\ ${ }^{2}$ School of Architecture, Civil and Environmental Engineering, Ècole Polytechnique Fèdèrale de Lausanne, \\ Lausanne, Switzerland \\ ${ }^{3}$ Dipartimento di Idraulica, Transporti e Infrastrutture Civili, Politecnico di Torino, Turin, Italy
}

Received: 19 July 2011 - Published in The Cryosphere Discuss.: 22 August 2011

Revised: 11 November 2011 - Accepted: 16 November 2011 - Published: 30 November 2011

\begin{abstract}
Mountain snow covers typically become patchy over the course of a melting season. The snow pattern during melt is mainly governed by the end of winter snow depth distribution and the local energy balance. The objective of this study is to investigate micro-meteorological processes driving snow ablation in an Alpine catchment. For this purpose we combine a meteorological boundary-layer model (Advanced Regional Prediction System) with a fully distributed energy balance model (Alpine3D). Turbulent fluxes above melting snow are further investigated by using data from eddy-correlation systems. We compare modeled snow ablation to measured ablation rates as obtained from a series of Terrestrial Laser Scanning campaigns covering a complete ablation season. The measured ablation rates indicate that the advection of sensible heat causes locally increased ablation rates at the upwind edges of the snow patches. The effect, however, appears to be active over rather short distances of about 4-6m. Measurements suggest that mean wind velocities of about $5 \mathrm{~m} \mathrm{~s}^{-1}$ are required for advective heat transport to increase snow ablation over a long fetch distance of about $20 \mathrm{~m}$. Neglecting this effect, the model is able to capture the mean ablation rates for early ablation periods but strongly overestimates snow ablation once the fraction of snow coverage is below a critical value of approximately 0.6 . While radiation dominates snow ablation early in the season, the turbulent flux contribution becomes important late in the season. Simulation results indicate that the air temperatures appear to overestimate the local air temperature above snow patches once the snow coverage is low. Measured turbulent fluxes support these findings by suggesting a stable internal boundary layer close to the snow surface causing a strong decrease of the sensible heat flux towards the snow cover.
\end{abstract}

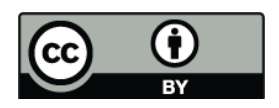

Correspondence to: R. Mott (mott@slf.ch)
Thus, the existence of a stable internal boundary layer above a patchy snow cover exerts a dominant control on the timing and magnitude of snow ablation for patchy snow covers.

\section{Introduction}

In mountains the snow cover becomes patchy over the course of the melting season. The patchiness of a snow cover can be attributed to the interaction between spatially variable snow-depth distribution at the time of peak accumulation (Luce et al., 1998; Liston et al., 2007; Anderton et al., 2004; Grünewald et al., 2010; Egli et al., 2011) and the local energy balance at the snow surface. As shown by several studies (e.g. Pomeroy et al., 1998; Liston and Sturm, 2002; Mott and Lehning, 2010; Clark et al., 2011), the end of winter snow cover can be highly variable due to wind-induced snow-transport processes, consisting of saltation, suspension and preferential deposition of precipitation (Lehning et al., 2008; Dadic et al., 2010).

In this study, several research fields regarding snow ablation are investigated. These are the development of internal boundary layers above patchy snow covers, the local advection of sensible heat over heterogeneous surfaces, the relative contribution of energy fluxes to snow ablation and the spatial variability of snow water equivalent. In the following we give a brief overview of the state of the art of these research fields.

Although solar radiation provides the dominant source of energy for snow ablation, turbulent heat transfer also contributes to snow ablation, especially in mid-latitudes, open landscapes and wind-exposed areas (Cline, 1997; Essery et al., 2006; Pohl et al., 2006). Once the snow cover is patchy, thermal internal boundary layers (e.g. Takahara and Higuchi, 1985; Marsh and Pomeroy, 1996) develop above the heterogeneous surface. As a result, local advection of warm

Published by Copernicus Publications on behalf of the European Geosciences Union. 
air from adjacent bare ground to the snow surface provides an additional source of energy contributing to snow ablation (e.g. Shook, 1995; Liston, 1995; Marsh and Pomeroy, 1996). In contrast, the existence of stable internal boundary layers above snow counteracts the local advection by suppressing turbulent exchange of sensible heat towards the snow surface. However, the interaction between all these driving processes acting on various scales is difficult to analyze and predict. In the Alpine environment in particular, additional factors affect the turbulent transfer of heat over snow, including thermal wind regimes and topographically induced wind velocity patterns (Male and Granger, 1981; Raderschall et al., 2008).

Several studies on local advection of sensible heat attempted to estimate the advective flux over snow fields by applying analytical methods (Shook et al., 1993; Shook, 1995), numerical atmospheric boundary-layer models (Liston, 1995; Essery, 1997), concepts of advection efficiency (Marsh and Pomeroy, 1996) or boundary layer integration methods (Granger et al., 2002; Essery et al., 2006). Measurements of either the effect of local advection of heat or the growth of internal boundary-layers above snow patches are extremely rare, except for the studies of Takahara and Higuchi (1985) and Granger et al. (2006). Essery et al. (2006) applied boundary layer principles and estimated the additional sensible heat flux to melting snow. Nevertheless, none of these studies demonstrated the direct effect of advective fluxes on the spatial distribution of snow ablation by measurements.

In recent years, extensive research into the main processes driving the spatial variability of snow water equivalent (SWE) has been carried out (Male and Granger, 1981; Pomeroy et al., 1998; Blöschl, 1999; Marks et al., 1999; Lehning et al., 2006; Bewley et al., 2010). Several studies focused on the relative importance of the energy contributed by solar radiation versus turbulent fluxes (Morris, 1989; Cline, 1997; Pohl and Marsh, 2006). These studies, however, are based on studies using model resolutions of $100 \mathrm{~m}$ or coarser and lack sufficient measurements of the spatial variability of snow ablation.

Turbulent heat fluxes are approximately linearly dependent on the local wind speed. Thus the topographically induced air flow is essential for calculating the spatial distribution of the turbulent exchange of sensible heat. Nonetheless, most studies assume constant wind velocities over the model domain. The study of Pohl et al. (2006) addressed the smallscale variability of turbulent fluxes related to topographically induced wind speed variations. Even if the study could demonstrate the importance of the impact of wind fields on the variability of turbulent fluxes, only a very simple model was used to simulate topographically induced near-surface wind field at a scale of $40 \mathrm{~m}$.

Grünewald et al. (2010) investigated the spatial patterns of snow ablation in an Alpine catchment (the Wannengrat area) on a very small scale of $2.5 \mathrm{~m}$ using Terrestrial Laser Scanning measurements. Although they observed highly variable ablation rates, they found only a weak correlation of the spatial variability of ablation rates with meteorological and terrain parameters. A different study at the same test site (Egli et al., 2011) demonstrated that, if the initial snow depth distribution at the beginning of the melt season is known, the development of total snow covered area could be predicted by spatially constant melt rates. At the Wannengrat testsite, the snow depth distribution was proven to be highly affected by the local wind field (Mott et al., 2010) leading to an end of winter snow depth distribution with a high inter- and intra-annual consistency (Schirmer et al., 2011). Schirmer et al. (2011) found correlations ranging between $r=0.97$ and $r=0.93$ for the end of winter snow depth distribution of two consecutive years.

The purpose of this study is to combine high-resolution measurements of the spatio-temporal snow ablation patterns at the Wannengrat test site with a fully distributed energy balance model and an atmospheric prediction model. We aim to analyze the complex interaction between atmospheric forces and spatio-temporal dynamics of the snow depth distribution driving snow ablation on a very small scale of $5 \mathrm{~m}$. We address three main points concerning the understanding of small-scale snow ablation in an Alpine catchment: First, we discuss the different energy terms contributing to the spatial variability of snow ablation including net solar radiation, turbulent flux exchange of sensible and latent heat and the effect of local advection of sensible heat. We investigate the appearance of snow-free patches as controlled by wind-dependent spatial distribution of snow depths at the beginning of the ablation season and by the wind-dependent spatially variable turbulent fluxes. Second, we compare the measured and modeled temporal dynamics of snow ablation. Here, we also focus on the relative importance of radiationdriven ablation versus turbulent heat exchange-driven ablation. These investigations lead us to the final part of the paper, which deals with the existence of stable internal boundary layers and its impact on snow ablation calculations. We discuss measured and modeled turbulent exchange of sensible heat over a melting snow surface as well as the validity of the constant flux layer assumption in energy balance models.

\section{Methods}

\subsection{Study site}

The study was conducted at two mountain sites (Fig. 1), located in the region of Davos (Switzerland). The investigation into the spatial variability of snow ablation was performed in an Alpine catchment, located in the Wannengrat area (Fig. 1b), where several studies on snow depth variability, snowpack stability and snow-hydrology have been completed in recent years (Mott et al., 2010; Grünewald et al., 2010; Bellaire and Schweizer, 2011; Grünewald and Lehning, 2011; Groot Zwaaftink et al., 2011; Schirmer et al., 


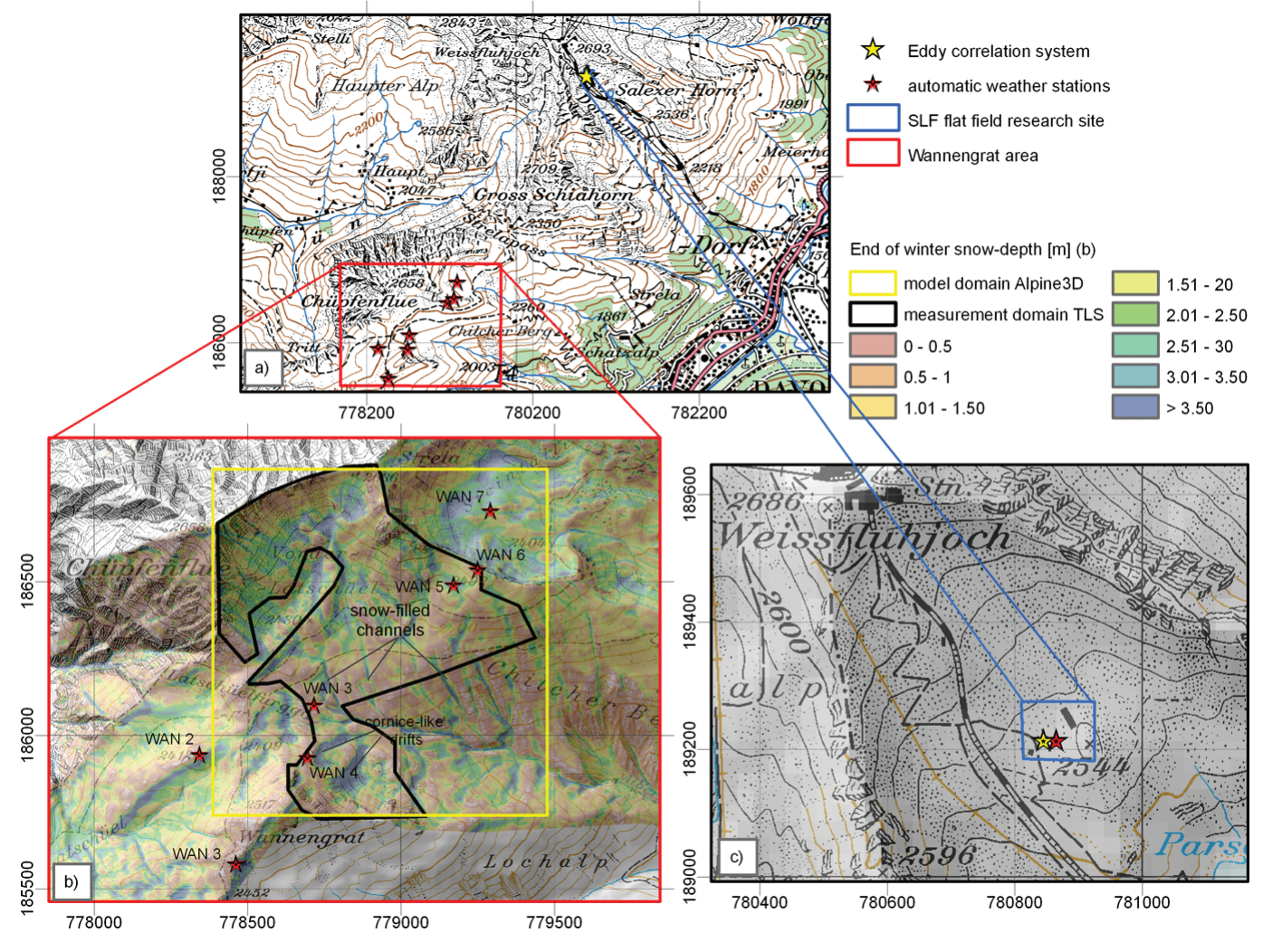

Fig. 1. Overview of the study sites (a), detailed maps of study sites Wannengrat area (b), and SLF flat field research site Versuchsfeld Weissfluhjoch (c). Borders of the measurement domain (black box in panel b) vary with snow coverage. The $\mathrm{x}$ - and $\mathrm{y}$ axes give Swiss coordinates in meters. (base map: Pixelkarte PK25 swisstopo (dv033492))

2011; Egli et al., 2011). The elevation ranges from 1940 to $2658 \mathrm{~m}$ a.s.l. and is above the local tree line. The Wannengrat area is equipped with seven automatic weather stations.

The second part of study, focusing on turbulent fluxes above melting snow was conducted on the flat field research site Versuchsfeld Weissfluhjoch (2540 m) (Fig. 1c) (e.g. Fierz and Lehning (2001); Stössel et al. (2010)) located northeast of the Wannengrat area. The research site Versuchsfeld has been a permanent field site since 1936 and is equipped with a large number of manual and automatic measurement devices required for snow research.

\subsection{Measurements: Wannengrat catchment}

\subsubsection{Snow depths and ablation rates}

During spring 2009, seven Terrestrial Laser Scanning (TLS) campaigns were conducted to obtain snow-depth changes covering six ablation periods from 31 March 2009 (time of peak accumulation of winter 2008/2009) to 9 June 2009. In spring 2011, another two measurement campaigns were carried out, but only for a small isolated snow patch. In this study we analyze five ablation periods in the ablation season
2009 and one ablation period in the ablation season 2011 (Table 1). One airborne laser scan (ALS) was performed on 9 April 2009 (Fig. 1b) to procure the complete coverage of the end of winter snow-cover (Mott et al., 2010; Grünewald and Lehning, 2011), which serves as an important input for energy balance modeling (see Sect. 2.5). For a detailed description of the measurement set-up and verification of TLS in the Wannengrat area, see Grünewald et al. (2010) and Schirmer et al. (2011). A more general description of TLS measurements on snow can be found in Prokop (2008), Prokop et al. (2008) and Schaffhauser et al. (2008). Grünewald et al. (2010) evaluated the accuracy of the ALS and TLS systems by comparing the data with each other and with a tachymeter survey, which was performed simultaneously. Compared to the tachymeter, they found a mean deviation in z-direction of less than $5 \mathrm{~cm}$ for TLS measurements.

In this study, we used measured snow-depth changes, obtained from the TLS to determine mean daily ablation rates. The modeled and measured snow depth change (dHS) and the modeled change in snow water equivalent (dSWE) are always given as a daily mean. In Table 1 measured and modeled mean daily dHS are listed for all periods discussed in this study. The prevailing wind direction, the mean wind 
Table 1. Measured ablation periods (P) for the ablation season 2009 and ablation season 2011 used for the current analysis with start and end date (time), prevailing wind direction (dir) $\left[^{\circ}\right]$ measured at wind station (WAN3), mean wind velocity $(\bar{U})[\mathrm{m} / \mathrm{s}]$ and height $(\mathrm{h})[\mathrm{m}]$ of wind velocity measurements for respective period, modeled snow-coverage at the start of the period $(\mathrm{F})$, measured mean daily change in snow depth (dHS) [m/d] and modeled mean daily change in snow depth (dHS M1) [m/d]

\begin{tabular}{cccccccccc}
\hline P & Time & dir & $\bar{U}$ & $\mathrm{~h}$ & $F$ & dHS & dHS M1 & Advection Analysis & Ablation Simulations \\
\hline P2 & $01 / 5-12 / 5 / 09$ & NW & 3.0 & 2.8 & 0.96 & 0.03 & 0.03 & Yes & Yes \\
P3 & $12 / 5-15 / 5 / 09$ & NW & 2.7 & 3.1 & 0.75 & 0.06 & 0.06 & Yes & Yes \\
P4 & $15 / 5-20 / 5 / 09$ & NW/SE & 2.6 & 3.2 & 0.62 & 0.04 & 0.05 & No & Yes \\
P5 & $20 / 5-25 / 5 / 09$ & NW & 3.6 & 3.5 & 0.47 & 0.04 & 0.08 & Yes & Yes \\
P6 & $25 / 5-02 / 6 / 09$ & NW & 3.5 & 3.9 & 0.33 & 0.02 & 0.02 & Yes & Yes \\
P7 & $11 / 04 / 11$ & NW & 5.3 & 3.4 & x & x & x & Yes & No \\
\hline
\end{tabular}
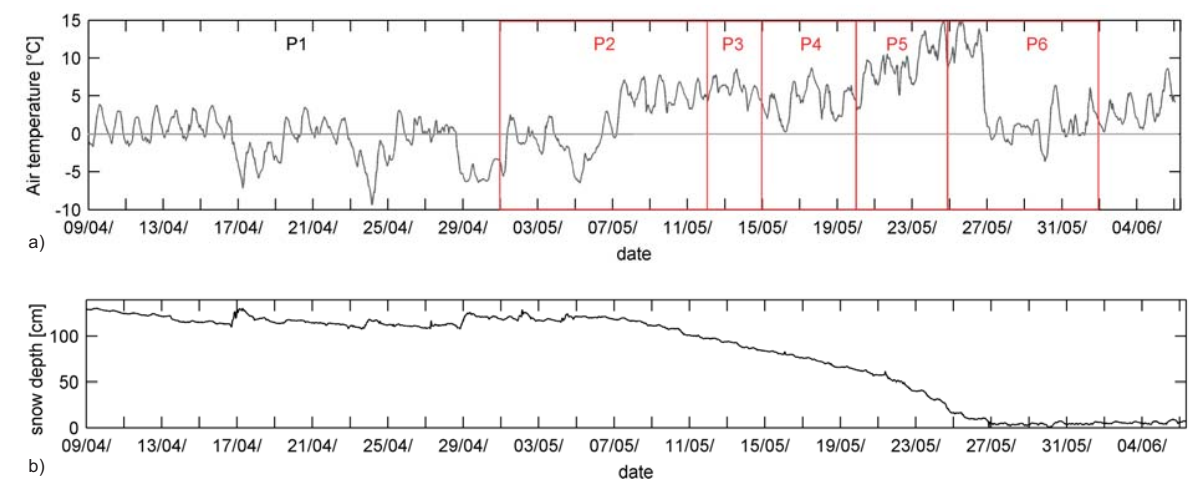

Fig. 2. Hourily time series of air temperature $\left[{ }^{\circ} \mathbf{C}\right]$ (a) and snow depth (b) obtained from weather station WAN3 for ablation season 2009.

velocity $(\bar{U})$ and the modeled snow-coverage $(F)$ at the start of the respective ablation period are also shown in Table 1.

In Fig. 2, the time series of measured air temperature is shown for the ablation period starting at the date of the ALS campaign. In this study we only analyze P2-P6, because snow melt only started around 1 May, 2009 (Egli et al., 2011). The numerical analysis starts already on 9 April 2009, the time of the ALS measurement campaign.

\subsubsection{Analysis of the influence of local advection of sensible heat on ablation rates}

Measured ablation rates were not only used for model validation, but also to investigate increased ablation rates on the upwind edge of snow patches. We assumed these edge effects to be an indicator of the magnitude of the local advection of sensible heat from adjacent bare ground to the snow cover. We therefore analyzed ablation rates as a function of the distance from the upwind edge of the snow patches. Six periods were subjected to the analysis, four periods of ablation season 2009 (P2, P3, P5, P6) and one single day in ablation season 2011 (P7). For the periods P2-P6 the entire area measured by the TLS was analyzed. Here the ablation periods typically lasted for 3-5 days. For these periods we observed a strong influence of early melt-out of snow-covered pixels at snow patch boundaries due to the long duration of ablation periods. For this reason we measured a small isolated snow patch with the TLS, once in the early morning and once in the evening in spring 2011 (P7). Thus P7 lasted only 9 hours assuring that almost no cells melted out during the measurement period.

We chose to analyze only those ablation periods which were characterized by one clear prevailing wind direction. Based on this criterion, Period P4 was excluded from the analysis, since no clear prevailing wind direction was detectable. First, the running average of the mean daily ablation rate for each distance class was calculated for all snowcovered cells. Distance classes were defined by the distance of each snow-covered cell from the upwind edge of the respective snow patch. Snow patch boundaries were obtained from high-resolution orthophotos, also taken simultaneously with the TLS measurements. We applied two different methods to calculate the running averages:

- Method 1: We only analyzed the cells which were still snow-covered at the end of the respective ablation period. In this method, cells at the snow patch boundaries are excluded from the analysis even if they showed very high ablation rates. This method was only applied for 
P7, where the short period led only to a few cells with complete melt.

- Method 2: In order to include the boundary cells, for which the snow disappeared during the analysis period and which showed significantly high ablation rates in the analysis, i.e. had enough snow at the beginning of the period to warrant consideration, we introduced an alternative criterion: all cells which were snow-covered at the start of ablation period and which showed daily ablation rates above the area-wide mean daily ablation rate were included in the analysis. The mean area-wide ablation rate was calculated from those cells which were snow-covered at the end of the respective ablation period. Method 2 was applied for P2, P3, P5 and P6, where considerable melt-out effects were observed.

Finally we normalized the ablation rates by the mean of all ablation rates incorporated in the analysis of the respective ablation period. The analysis suggested that when using measurement windows longer than one day, the second method assures that important snow-covered cells with high ablation rates at the snow patch boundaries are subjected to the analysis.

\subsection{Measurements: SLF flat field research site Versuchsfeld Weissfluhjoch}

\subsubsection{Turbulent flux of sensible heat over melting snow}

Turbulent fluxes of sensible heat were investigated by applying the eddy-covariance method (see Eq. 1) to data from two 3-D ultrasonic anemometers CSAT3 (Campbell Scientific, Inc.,) at approximately 2 and 4 meters above the snow surface (Stössel et al., 2010). Measurements were acquired at a frequency of $20 \mathrm{~Hz}$. We analyzed data from 1 April 2007 until 25 April 2007, when the snow cover was already melting. Air pressure, relative humidity and air temperature were obtained from sensors on a state of the art weather station to calculate air properties required for processing the turbulence data (e.g. the specific heat capacity of air and specific humidity). The weather station is also located at the SLF flat field research site, where data is available in $30 \mathrm{~min}$ intervals. The height of the temperature sensor at the weather station corresponds to the height of the upper ultrasonic anemometer.

The sensible heat flux $Q_{\mathrm{s}}$ is calculated from the covariance between the perturbation values of the vertical wind velocity $w$ and the virtual potential temperature $\theta_{\mathrm{v}}$ multiplied by the density of air $\rho$ and the heat capacity of air $c_{\mathrm{p}}$ :

$$
Q_{\mathrm{s}}=\rho c_{\mathrm{p}} \overline{w^{\prime} \theta_{\mathrm{v}^{\prime}}}
$$

The turbulence data were averaged to $30 \mathrm{~min}$ intervals. Test studies indicate that the dependence of turbulent fluxes on the averaging time ( $15 \mathrm{~min}$ versus $30 \mathrm{~min}$ ) is very small (not shown).

\subsection{Numerical models}

We compute snow ablation for the Wannengrat catchment by combining a three-dimensional meteorological model with a fully distributed energy balance model, using a horizontal grid resolution of $5 \mathrm{~m}$. The energy balance model is part of the model system Alpine3D, developed to calculate Alpine snow surface processes (Lehning et al., 2006; Bavay et al., 2009; Mott and Lehning, 2010). Alpine3D is based on the fully distributed version of the snow-cover module SNOWPACK (Lehning and Fierz, 2008) and enables the calculation of snow drift including sublimation (Lehning et al., 2008; Mott and Lehning, 2010; Groot Zwaaftink et al., 2011), the energy balance (Helbig et al., 2009, 2010) and runoff. In this study we applied the user-defined model coupling consisting of the modules SNOWPACK, runoff and the energy balance. The energy balance module supports shading, surface reflections of shortwave radiation and emission of long-wave radiation (Bavay et al., 2009). Turbulent fluxes are calculated using the Monin-Obukhov bulk formulation which is based on local roughness length, wind speed and an estimation of atmospheric stability calculated by the temperature difference between the surface, $s$, and the air at some reference height, $z_{\text {ref }}$. The sensible $Q_{\mathrm{s}}$ and latent heat flux $Q_{1}$ are calculated from the following equations:

$Q_{\mathrm{s}}=\mathrm{C} \rho c_{\mathrm{p}} \bar{U}\left(T_{\mathrm{z}_{\mathrm{ref}}}-T_{\mathrm{s}}\right)$

$Q_{1}=\mathrm{C} \rho L_{\mathrm{v}} \bar{U}\left(q_{\mathrm{z}_{\mathrm{ref}}}-q_{\mathrm{s}}\right)$

where $\mathrm{C}$ is the exchange coefficient for heat, momentum and water vapor (see below), $\rho$ the density of air, $c_{\mathrm{p}}$ the heat capacity of air, $L_{\mathrm{v}}$ the latent heat of sublimation for ice, $\bar{U}$ mean wind velocity, $T_{\mathrm{z}_{\mathrm{r}} \text { ef }}$ is the air temperature at the reference height and $T_{\mathrm{S}}$ is the snow surface temperature. $q_{\mathrm{z}_{\mathrm{r}}}$ and $q_{\mathrm{s}}$ are specific humidity at the snow surface and at the reference height. The surface layer is defined as a constant flux layer. Therefore, fluxes at any height are assumed to be equal to the surface flux.

The exchange coefficient $\mathrm{C}$ depends on the instrument height $z$ and surface roughness length $z_{0}$ and is calculated in a simplified way not distinguishing roughness lengths for scalars and momentum (Calenca, 2001):

$\mathrm{C}=\frac{k^{2}}{\ln \left(\frac{z}{z_{0}}\right)^{2}}$

Taking into account the snow-covered topography, we used a surface roughness length of $z_{0}=0.005 \mathrm{~m}$, which is in agreement with typical values for snow (Doorschot et al., 2004) and (Manes et al., 2008). Note that roughness lengths for momentum $z_{0}$, heat $z_{\mathrm{H}}$ and moisture $z_{\mathrm{Q}}$ are approximated to be equal. Considering the snow-covered surface we used a modified version of the stability correction functions of Stearns and Weidner (1994) to correct the heat exchange coefficient for stability, $\psi(\mathrm{z} / \mathrm{L})$, as described in Michlmayr et al. (2008). 
$\psi$ is a function of height above the surface $z$ and of the Monin Obukhov length $L$ :

$L=\frac{-\bar{\theta}_{\mathrm{v}} u_{*}^{3}}{k g\left(\overline{w^{\prime} \theta_{\mathrm{v}}}\right)_{\mathrm{s}}}$

where $\theta_{\mathrm{v}}$ is the virtual potential temperature, $u_{*}$ the friction velocity, $k$ the von Karman constant and $g$ the gravitational constant. For a detailed description of the stability correction function used in Alpine3D, see Michlmayr et al. (2008).

The model can be run with a correction for atmospheric stability or without stability correction assuming the local atmosphere to be neutrally stratified. Advection of sensible heat is neglected in the current version of Alpine3D.

The calculation of the surface albedo is based on an empirical approach. The albedo function takes into account meteorological factors (air temperature, relative humidity, incoming shortwave radiation, wind velocity), an aging factor and the modeled current state of the snow surface (density, volumetric content, grain properties). For a detailed description of the albedo function, see Lehning et al. (2002) and Michlmayr et al. (2008).

To account for the spatial variability of turbulent fluxes as a function of local flow conditions, we drive the energy balance module of Alpine3D with high-resolution atmospheric flow fields, calculated with the non-hydrostatic and atmospheric prediction model Advanced Regional Prediction System (ARPS) (Xue et al., 2004). We only use the flow field for the first layer above ground with a horizontal grid resolution of $5 \mathrm{~m}$. Due to a terrain-following grid the vertical resolution varies between $0.5 \mathrm{~m}$ at ridges and $1.1 \mathrm{~m}$ at flatter terrain. A more detailed description of the model setup of ARPS is given by Mott et al. (2010). The ARPS flow fields were chosen as an hourly input for Alpine3D by using a classification scheme based on the frequency distribution of the measured wind velocity and the wind direction at the wind station (WAN3) (Fig. 1) for the specific time step. As shown by previous studies (e.g. Grünewald et al. (2010); Egli et al. (2011)) the end of winter snow distribution appears to be a dominant factor driving the spatially variable snow melt processes as well as the melt-out of the seasonal snow cover. We therefore consider the snow-depth distribution at the start of the ablation season by initializing the Alpine3D model with snow depths measured by ALS at the time of peak accumulation, 9 April 2009 (Fig. 1) (Mott et al., 2011).

The mean snow density for the snow-cover initialization was derived from manual measurements. The spatial variability of snow density is small compared to snow depth (e.g. Dickinson and Whiteley (1972); Pomeroy and Gray (1995); Jonas et al. (2009)). Following these studies, Grünewald et al. (2010) analyzed the spatial distribution of snow density in the Wannengrat catchment as a function of incoming solar radiation and time of season. They found that only the time of season has a significant effect on snow density. We therefore assume the initialized mean snow-density of $310 \mathrm{kgm}^{-3}$ to be spatially homogeneous. Initialized snowpack temperatures were obtained from a nearby permanent weather station and assumed to be spatially homogeneous as well. At the time of initialization,he snowpack was near isothermal.

For the calculation of the spatial variability of daily ablation rates on the Wannengrat study site, three different model setups of Alpine3D were used in order to account for the effect of the spatial variability of wind velocity and the effect of stability correction in the model:

- M1: The energy balance model of Alpine3D is driven by meteorological input (air temperature, relative humidity, incoming longwave radiation, incoming shortwave radiation, precipitation) from a single weather station located in the study area (WAN 3). In addition, we use wind velocities on a grid with $5 \mathrm{~m}$ resolution obtained from mean flow fields calculated with ARPS. The correction for atmospheric stability is enabled.

- M2: The same set-up as for M1, but without correction for atmospheric stability. The local atmosphere is assumed to be neutrally stratified.

- M3: The energy balance model of Alpine3D is driven by meteorological input from a single weather station located in the study area (WAN 3), including wind velocity. The correction for atmospheric stability is enabled.

In the distributed version of SNOWPACK, as used for the Wannengrat catchment, turbulent fluxes are calculated using Neumann boundary conditions. In the single point application of SNOWPACK on the Versuchsfeld study site, we use Dirichlet boundary conditions as long as no melt occurred. The Dirichlet boundary conditions assure that the model is forced to reproduce the surface temperature as measured. Once the snow cover is at its melting point, Neumann boundary conditions were used to solve for the energy balance (Bartelt and Lehning, 2002).

\section{Results and discussion}

\subsection{Local advection of sensible heat}

In Fig. 3 the normalized running averages of snow-depth changes (dHS) are shown per distance class of $1 \mathrm{~m}$. All ablation periods subjected to the analyzes are characterized by a northwesterly wind direction. Note that we used only pixels that did survive the full period for P7 and all pixels with significant melt for the other periods (see Subsect. 2.3). All of the periods showed significantly higher ablation rates at the upwind edges of the snow patches than further downwind. This indicates that the snow patches are highly affected by local advection of sensible heat at their upwind edges. The 

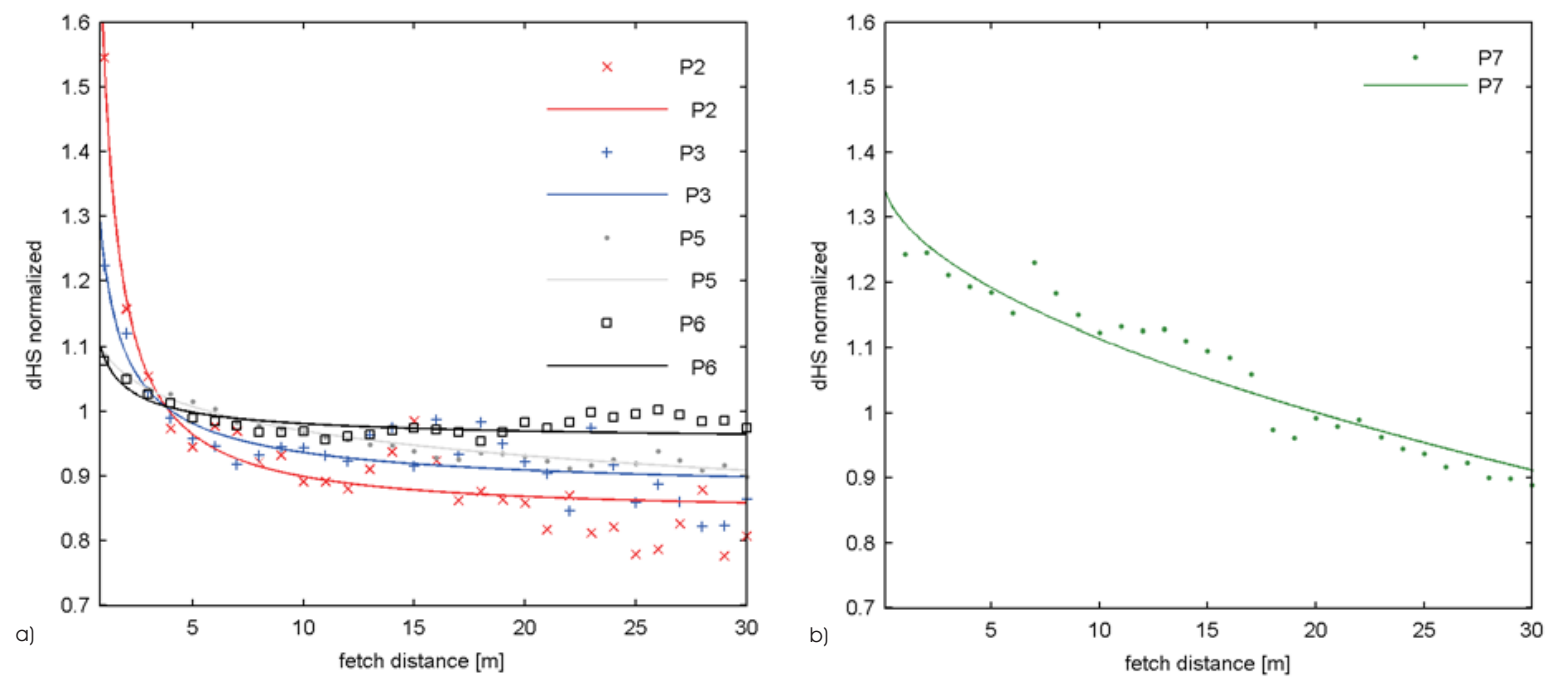

Fig. 3. Normalized averaged snow-depth changes per distance class of $1 \mathrm{~m}$ in fetch distance from area-wide measurements of periods $\mathrm{P} 2$, P3, P5, P6 (a) and from an isolated snow patch at 11 April 2011 (b).

local significance of this effect is underlined by ablation rates being up to $60 \%$ larger at the upwind edges than average.

A link was observed between the magnitude of increased ablation at the upwind edge of snow patches and the areawide snow-coverage (F) (Table 1) as well as the mean wind velocity. The strongest advective effect occurs on the upwind edges, but the shortest distance (about $4 \mathrm{~m}$ ) until average snow ablation is reached, is evident for the early periods (P2 and P3). For later periods (P5 and P6) the slope of the ablation curve is less steep, but average ablation is observed after a distance of 5 to $6 \mathrm{~m}$.

By contrast, results for $\mathrm{P} 7$ suggest that advective processes are active over a longer distance. While at the upwind edge the ablation rates are about $30 \%$ above the mean ablation rate, mean ablation is first observed after a distance of $20 \mathrm{~m}$. One reason for the longer range of the impact of advective processes might be the significantly higher mean wind velocity observed for P7 (Table 1). These results show that a mean wind velocity of about $5 \mathrm{~m} \mathrm{~s}^{-1}$ is required for advective heat transport to be active over a long fetch distance of about $20 \mathrm{~m}$.

We conclude that the local advection causes strongly increased local ablation rates at the upwind edges of the snow patches, but the effect of local advection seems to be only dominant over rather short distances, except for situations with high mean wind velocities and a small snow-coverage. The later in the season and the lower the snow-coverage, the smaller the local effect of advection directly at the upwind edge, but the longer the distances over which advective processes appear to be active. This might be due to a generally higher amount of energy available for snow ablation acting over larger distances, fostered by high wind velocities (P5, P6, P7). A further reason is that the turbulent flow field advects heat not only from just one wind direction, if e.g. a snow patch is completely surrounded by a large area of snow free surface. As the fraction of bare ground increases, the impact of warmer bare ground tends to dominate the micro-meteorology of the entire area. Additionally the snow-cover became thin during the latter periods hence an increased number of cells were excluded from the analysis because of early melt-out.

\subsection{Spatial variability of daily ablation rates driven by various energy fluxes}

Five ablation periods were modeled using Alpine3D in order to investigate the spatial variability of daily ablation rates (Table 1) and to analyze the spatial distribution of snow ablation as a function of the spatially variable energy fluxes. For all simulations discussed in this section, the energy balance was driven by high-resolution atmospheric flow fields obtained from ARPS and the corrections for atmospheric stability were enabled (M1).

In Fig. 4 the spatial distribution of modeled dSWE are shown for ablation periods P2 (Fig. 4a), P3 (Fig. 4b), P4 (Fig. 4c), P5 (Fig. 4d) and P6 (Fig. 4e). The modeled results indicate a high spatial variability of dSWE for all modeled periods. Highest ablation rates are observed at lower altitudes, the sun-exposed slopes of the Chilcherberg and parts of the Vorder Latschüel and the Latschüelfurgga (Fig. 3). Areas at lower altitudes, at the Latschüelfurgga and the steep slopes of the Wannengrat summit become snow-free first.

The modeled contributions of the different energy terms to snow ablation are illustrated in Fig. 5 for the ablation period $\mathrm{P} 3$. In the Wannengrat area, most of the snow ablation is controlled by net radiation fluxes (Fig. 5a), except for some 

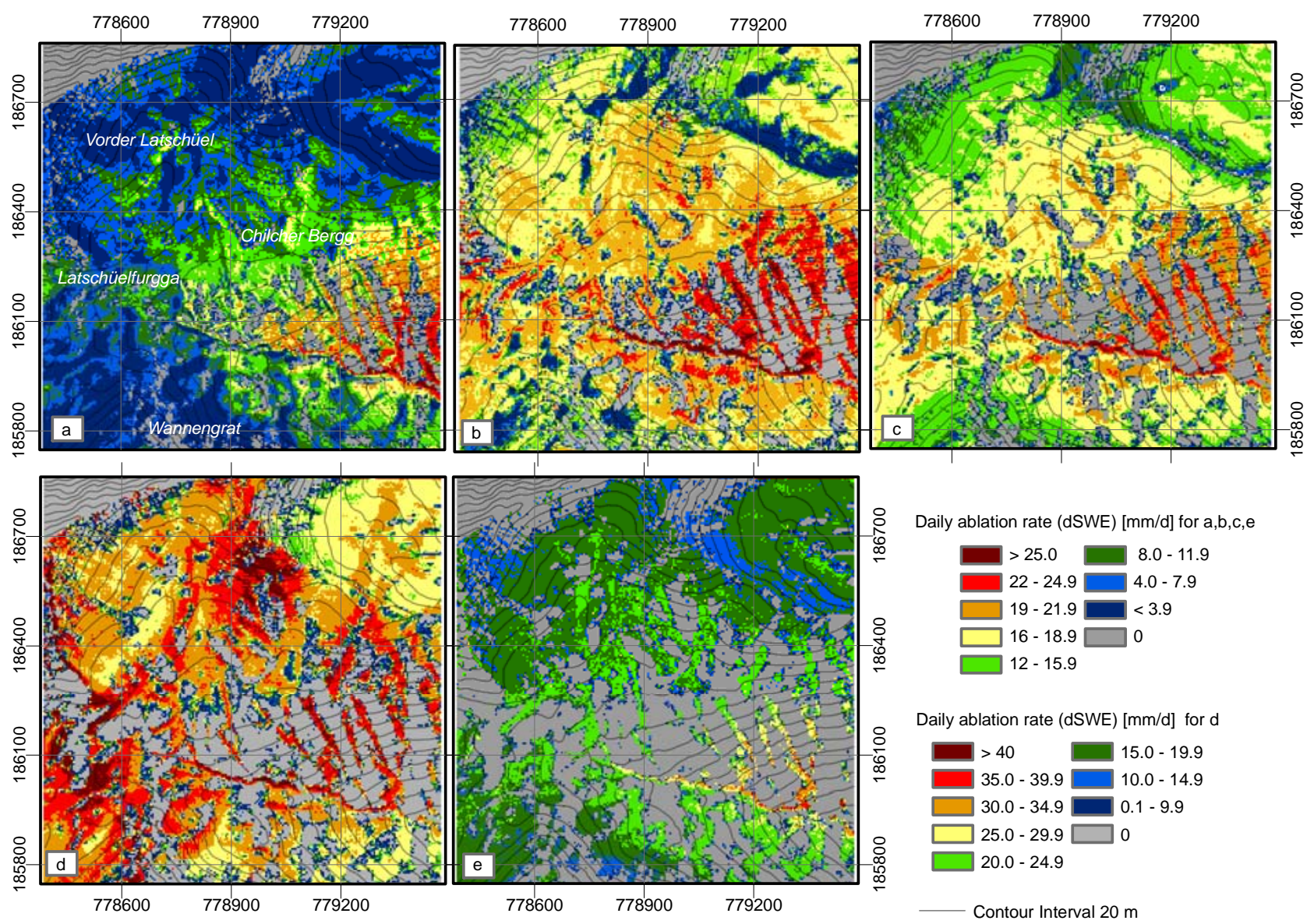

Fig. 4. Modeled daily ablation rates (dSWE) for ablation periods P2 (a), P 3 (b), P4 (c), P5 (d) and P6 (e). Note that legend is different for P5. The $\mathrm{x}$ - and y axes give swiss coordinates in meters. (base map: Pixelkarte PK25 swisstopo (dv033492))

wind-exposed areas provoking turbulent fluxes (Fig. 5b). Considerable contribution of net turbulent fluxes to snow ablation is primarily revealed at the Latschuelfurgga, the steep NE and NW slopes of the Wannengrat summit and at local areas at ridges and bumps (Fig. 5). These areas correspond well to areas of early melt-out and increased ablation rates (Fig. 4). Within these exposed areas, the net turbulent exchange of sensible and latent heat contributes 30 to $50 \%$ of the melt energy. The latent heat flux is, however, quite small. Thus sensible heat flux is the prime energy source for snow ablation due to turbulent exchange (not shown). As expected, model simulations driven by atmospheric flow fields indicate that the wind velocity distribution has a considerable local effect on the magnitude of the mean daily ablation rates, as turbulent fluxes are approximately a linear function of wind velocity.

Furthermore, as already suggested by Grünewald et al. (2010) and Anderton et al. (2004), the snow depth distribution at the end of the accumulation period (Fig. 1), appears to have a strong influence on the timing of melt-out. Snow-free patterns emerge first at ridges, bumps and wind-exposed slopes (Grünewald et al., 2010), provoked by enhanced wind velocities and thus reduced deposition and erosion of snow during the accumulation period (Mott et al., 2010). Snow patches tend to survive in channels and wind-sheltered slopes, characterized by low wind velocities and thus strong snow accumulation during winter (Fig. 4). Later in the ablation season, the survival of snow patches in accumulation areas is often further fostered by smaller wind velocities suppressing turbulent fluxes and thus diminishing snow ablation (Fujita et al., 2010). Such a negative feedback is visible in the bowl located at the foot of Vorder Latschüel (Bowl), where small wind velocities were observed and modeled (Mott et al., 2010) leading to high accumulation amounts during winter. This effect is further enhanced by avalanche deposits (Fig. 1) and small ablation rates during spring (Fig. 4).

The strongest influence of wind velocity on snow ablation and melt-out is visible at the Latschüelfurgga. This windexposed anticline features areas of high accumulation close to areas of thin snow cover, which promote the development 


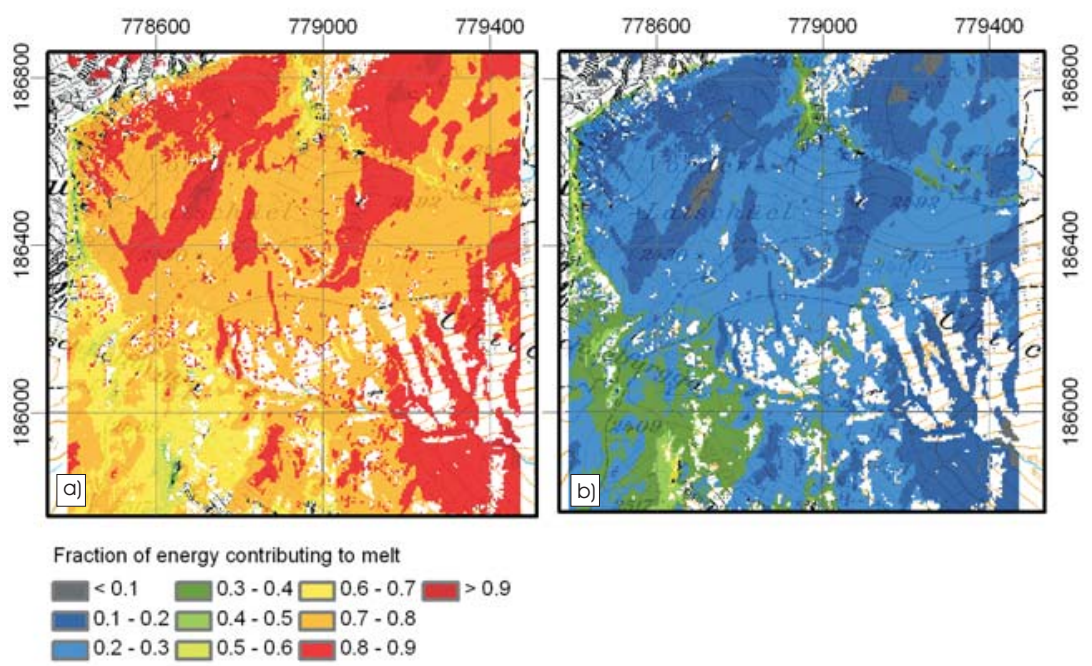

Fig. 5. Fractional energy contributing to snow melt during daytime of net radiation (a) and net turbulent energy (b) averaged for P3.

of patchy snow covers early in the ablation season. Once the snow cover is patchy, this area is more prone to melt-out due to the effect of local advection of sensible heat from adjacent bare ground to the snow surface, providing an additional source of energy contributing to snow melt. As explained above, this process has been neglected in the model simulations. Simulations driven by hourly wind velocities obtained from a single weather station (not shown) result in significantly lower ablation rates and a temporal shift of melt-out, especially at the Latschüelfurgga and the NE/NW slopes of the Wannengrat summit.

Comparing modeled ablation rates (as dHS) to measured ablation rates (as dHS) (Fig. 6) we also observe an enhanced decrease of snow depths for the NE slope of the Wannengrat summit and the SW slopes in the TLS measurements. Modeled and measured changes of snow depths indicate a strong ablation at two cornice-like drifts at the NE slope of the Wannengrat summit (Fig. 6). Model results suggest, however, that the snow-depth changes at the cornice-like drifts are driven by settling processes only affecting absolute snow depth changes and do not directly contribute to snow ablation as SWE (Fig. 4). Although the model is able to capture most spatial patterns of snow ablation, a considerable difference in spatial variability between modeled and measured ablation rates is observed in the bowl-shaped Vorder Latschüel (bowl) (Fig. 6c). The model strongly underestimates melt energy in the bowl, which we attribute to two main processes neglected in the model runs. First, the modeled NW wind fields show very small wind velocities within these slopes (Mott et al., 2010) involving strong suppression of turbulent fluxes (Fig. 5). Local thermal winds, which are reinforced once snow-free patches and rocks emerge, would enhance turbulent fluxes within the bowl. This process is neglected in the current setup of the atmospheric model. Second, we do not use the radiosity approach introduced by Helbig et al.
(2009) to study multiple, anisotropic terrain reflected radiation in complex terrain. The bowl is characterized by rocky and rough terrain which might be a considerable factor for increased energy supply to the snow cover.

We summarize that modeled results demonstrate that the patterns of early melt-out and the spatial variability of the snow ablation rates are not only driven by altitude and exposition but also by the small-scale spatial variability of wind velocities. Beside the local energy balance as a controlling factor, melt-out appears to be also controlled by the interaction of two main processes: The effect of snow depth distribution at the end of the accumulation season drives the appearance of snow-free patches and therefore the onset of local advection processes while the low wind velocities over the remaining snow patches suppress turbulent fluxes and ablation rates.

\subsection{Temporal development of ablation rates and energy fluxes in the course of the ablation season}

In Fig. 7 the temporal development of measured and modeled mean daily ablation rates (as dHS) is shown for the ablation season 2009. Modeled results for M1, M2 and M3 were analyzed for the area covered by TLS measurements which was still snow-covered at the end of the respective ablation period. Measurements show highest ablation rates for P3, with a daily decrease in snow depth of about $6 \mathrm{~cm}$. Even if model setup M1 (flow field and stability correction enabled) shows the best results, this mode is only able to capture mean daily ablation rates for the early ablation periods $\mathrm{P} 2$ and $\mathrm{P} 3$, but overestimates the ablation periods late in the ablation season (P4, P5, P6). In contrast, M3 (no atmospheric wind field, stability correction enabled) strongly underestimates early periods and overestimates periods late in the season. Modeled results of M2 show, that assuming a 

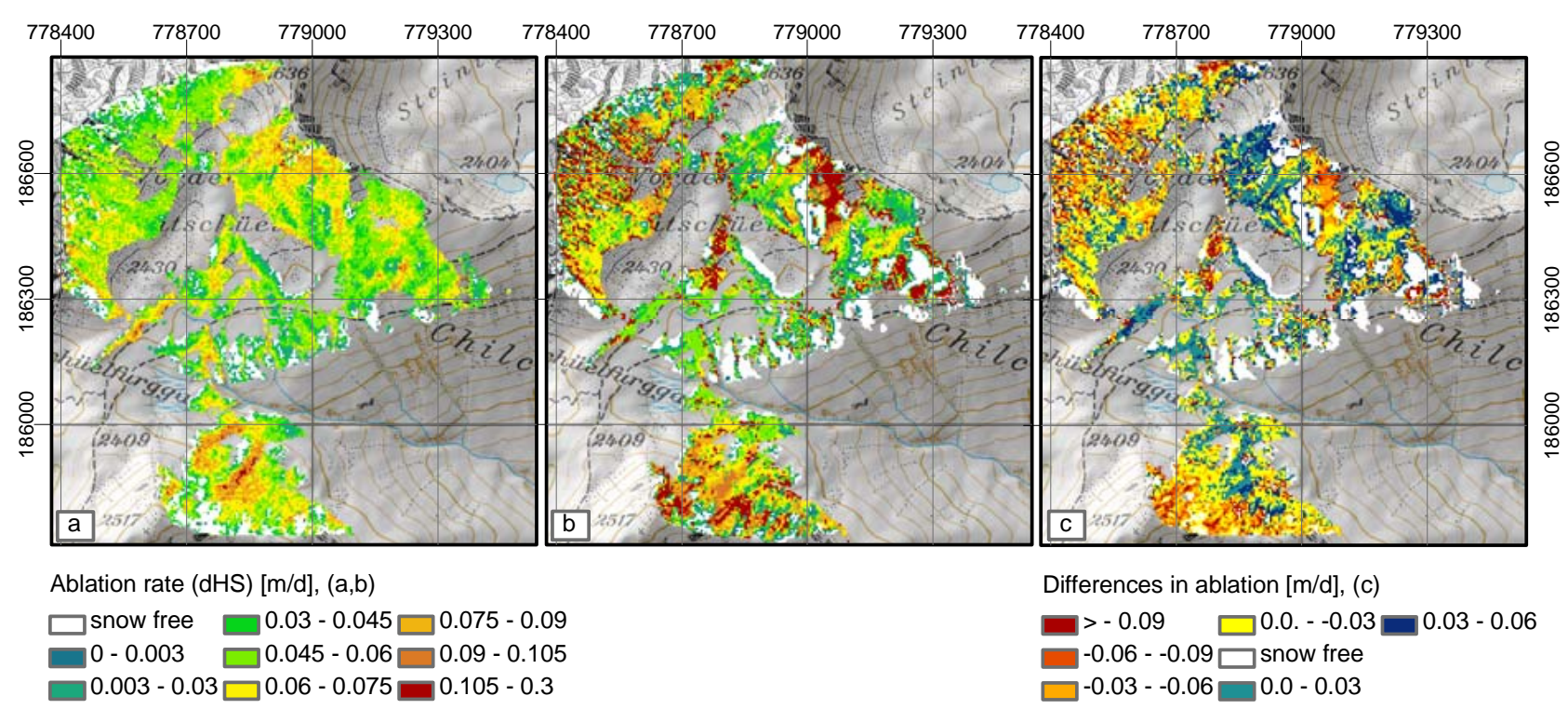

Fig. 6. Modeled (a) and measured (b) daily ablation rates in snow depth (dHS) averaged for the time period P3 (12-15 May, 2009 ). Differences between modeled and measured snow ablation (c). Negative values indicate an underestimation of snow ablation by the model. The $\mathrm{x}$ - and y axes give swiss coordinates in meters. (base map: Pixelkarte PK25 swisstopo (dv033492)).

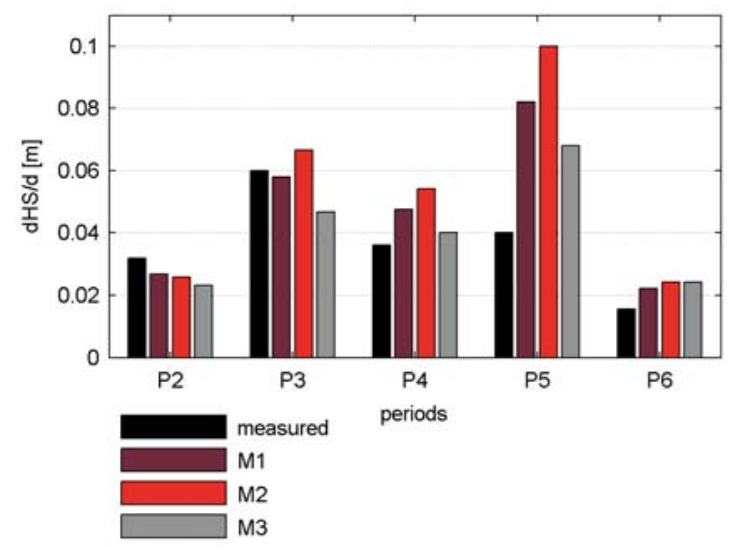

Fig. 7. Daily ablation rates averaged over the respective periods (measured and modeled). Modeled ablation rates are either calculated driven by wind velocity fields obtained from ARPS and with (M1) or without stability correction (M2) or driven by wind speed obtained from a single weather station and stability correction (M3).

neutral atmospheric layer causes a strong overestimation of turbulent fluxes leading to unrealistically high snow ablation. We summarize, that the model M1, which accounts for stability effects and for the spatial variability of wind velocities provides the best estimates of mean daily ablation rates. All models behave similarly in that they strongly overestimate ablation rates when snow coverage is between 60 and $30 \%$. For P5, the modeled ablation rate (M1) is even double of the measured one.
Mean daytime energy fluxes averaged over the five ablation periods are shown in Fig. 8 (M1) for snow-covered cells. Note that all energy fluxes are defined positive if directed towards the snowpack. It is evident that net radiation clearly dominates the total amount of melt energy $\left(Q_{\mathrm{m}}\right)$ early in the ablation season, while for the later ablation periods the sensible heat flux also becomes important. Especially for P5 the sensible heat flux $\left(Q_{\mathrm{s}}\right)$ contributes $35 \%$ to the net melt energy, mainly driven by a high mean air temperature (Fig. 2) accompanied by an above-average mean wind velocity (Table 1$)$. For this period, net melt energy $\left(Q_{\mathrm{m}}\right)$ averages $260 \mathrm{~W} \mathrm{~m}^{-2}$ during daytime. Measured ablation rates (as dHS) (Fig. 7) show, however, that melt energy must have been highest for $\mathrm{P} 3$, which only averages about $160 \mathrm{~W} \mathrm{~m}^{-2}$ for simulation results (Fig. 8). Snow depth change during early periods $\mathrm{P} 2$ and $\mathrm{P} 3$ might also be due to the settling process.

In previous studies, radiation-driven melt has been identified to be dominant early in the season while turbulent heat exchange-driven melt could be shown to gain importance late in the season (e.g. Shook et al. (1993)). In this study, however, we do not directly account for the local advection of sensible heat from bare ground to snow covered areas, but we indirectly account for the effect of heating of bare ground. The heating of bare ground is provoked by a significantly lower albedo for bare ground than for snow-covered areas. Also, the surface temperature of bare ground is not restricted to $0^{\circ} \mathrm{C}$.

Based on the large net melt energy produced in P5 (Fig. 8) and the related high ablation rates (Fig. 7), we observe that 


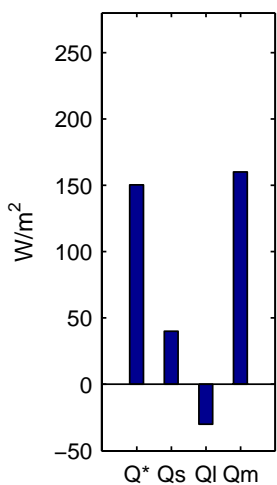

a) P2

$\mathrm{Qm}=\mathrm{Q}^{*}+\mathrm{Qs}+\mathrm{Q}$

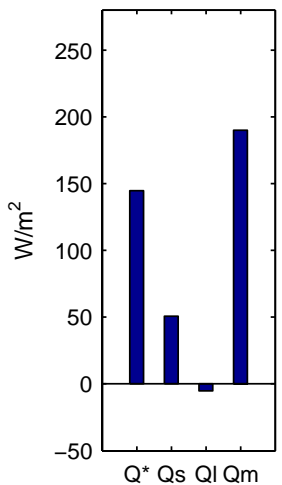

b) P3

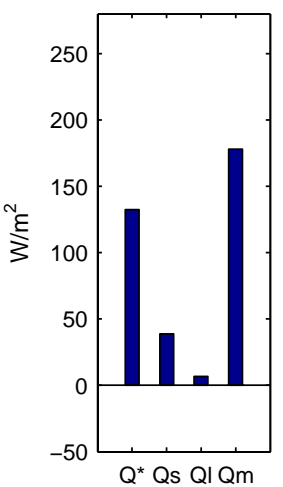

c) P4

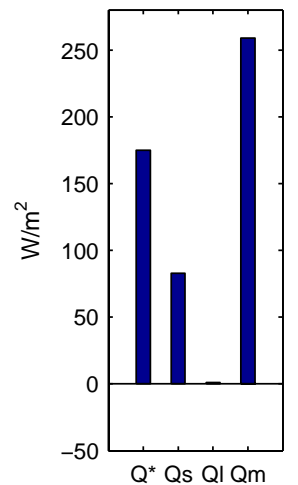

d) P5

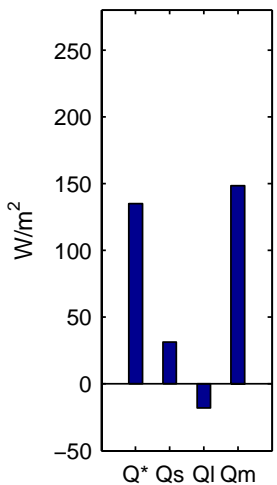

e) P6

Fig. 8. Modeled mean energy fluxes for ablation periods $\mathrm{P} 2$ (a), $\mathrm{P} 3(\mathbf{b}), \mathrm{P} 4(\mathbf{c}), \mathrm{P} 5$ (d) and $\mathrm{P} 6(\mathbf{e})$ : net radiation $\left(\mathrm{Q}^{*}\right)$, sensible heat flux $\left(Q_{\mathrm{S}}\right)$, latent heat flux $\left(Q_{1}\right)$, melt energy $\left(Q_{\mathrm{m}}\right)$ during daytime (7:00 a.m.-5:00 p.m. Local time) for snow covered cells at the end of the respective ablation period.

we strongly overestimate the effect of the turbulent exchange of sensible heat transported towards the snow surface late in the season. The overestimation of heat fluxes above snow is believed to be caused through the initialization of the energy balance model with the measured air temperatures at $3 \mathrm{~m}$ above ground. This temperature is not in surface equilibrium with the snow surface. Based on the constant flux layer assumption we simply integrate between the surface temperature values of snow and the atmospheric values (see Eq. 2), neglecting the atmospheric stability directly above the snow surface, which forms locally within a new stable internal boundary layer and effectively decouples the warmer temperatures from above.

\subsection{Turbulent exchange of sensible heat above a melting snow surface}

In the previous subsection we demonstrated that modeled snow ablation is overestimated as soon as snow-coverage is below a critical value. We hypothesized that the overestimation of snow ablation is evoked by overestimating the sensible heat flux towards the snow surface. The aim of this subsection is to support this hypothesis by investigating the measured turbulent exchange of sensible heat above a melting snow surface using the eddy-covariance method (see Eq. 1) and by comparing it to modeled turbulent heat fluxes using a Monin-Obukhov bulk formulation (see Eq. 2-4).

In Fig. 9a and Fig. 10a the turbulent exchange of sensible heat measured at two different instrument heights of approximately 2 and $4 \mathrm{~m}$ above the snow surface is compared to modeled fluxes at the snow surface for two measurement periods in spring 2007. For details on the measurement set-up and a validation of latent heat fluxes in February see also Stössel et al. (2010). Note that the common constant flux layer assumption allows us to compare vertical turbulent fluxes at different heights. The stability parameter $z / L$ Fig. (9b and Fig. 10b) was calculated from a statistical analysis of measured turbulence data (see Eq. 4). Measured air temperature, snow surface temperature and wind velocity obtained from a near-by weather station are illustrated in Fig. 9c and Fig. 10c. Note that positive snow surface temperatures are due to limitations in the accuracy of the infrared sensor.

On most days, the turbulent flux of sensible heat follows a clear diurnal variation (Fig. 9a, 10a). We observe positive sensible heat fluxes mostly starting shortly after noon and lasting until the evening. During the night, calm wind conditions suppress the turbulent exchange of sensible heat. Peak fluxes of sensible heat towards the melting snow surface are periodically observed some hours after the daily peak of air temperature in the afternoon. At this time, the snow surface has already been cooled by a negative energy balance, resulting in a strong temperature gradient between air and snow surface. Hours of peak sensible heat fluxes towards the snow surface additionally coincide with strong wind conditions, which are usually observed in the afternoon. These strong winds provoke turbulent exchange of the sensible heat flux by producing additional turbulence in the atmospheric surface layer due to wind shear. Therefore the daily maximum of the positive turbulent heat fluxes appears to be driven by a diurnal local thermal wind system prevailing in the afternoon. This thermal wind system is observed for all days shown in Fig. 9c and Fig. 10c, except for 14 April. Although the air temperature is high at 14 April (Fig. 9) only weak sensible heat fluxes towards the snow surface are observed due to very low wind velocities (Fig. 9c).

During the afternoon, $z / L$ indicates strongly stable conditions for both sensors. The lower sensor, however, reveals stronger statically stable conditions near the ground than the sensor above (Figs. 9a and 10a). 


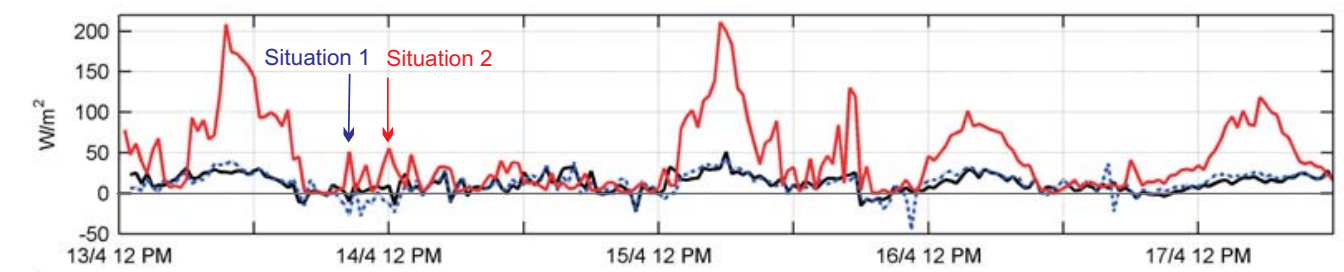

a

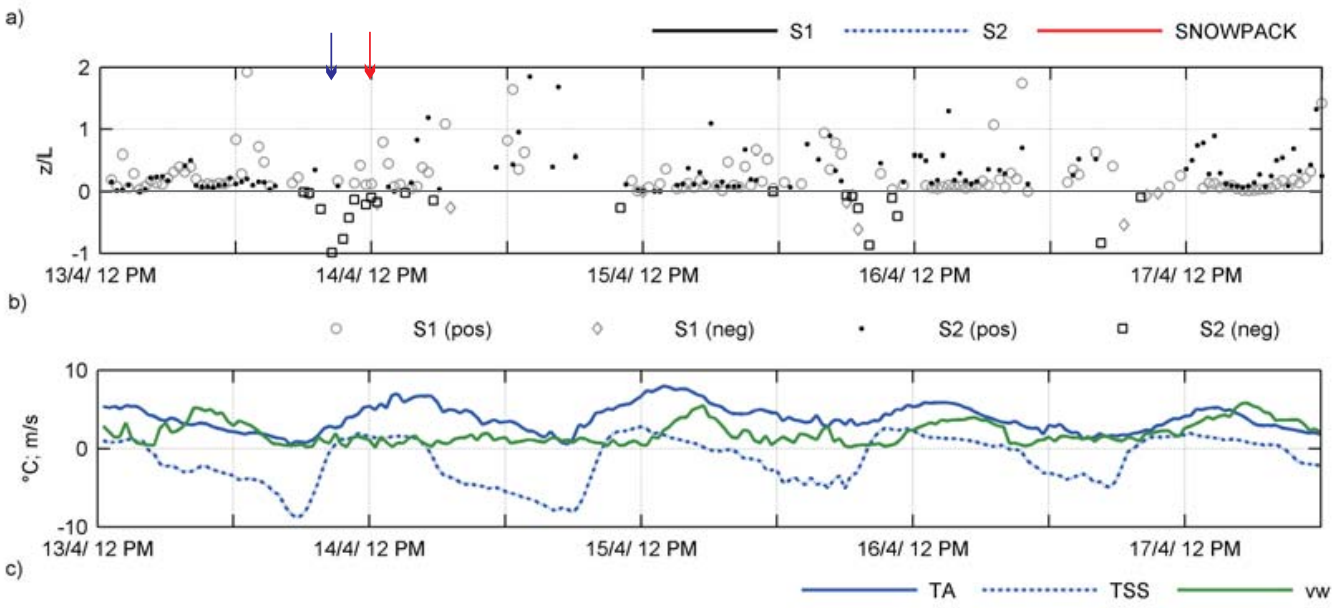

Fig. 9. Time series of measured turbulent heat fluxes $\left(Q_{\mathrm{S}}\right)$ at Sonic 1 (S1) and Sonic 2 (S2), and modeled heat fluxes (SNOWPACK) for time period 13-17 April 2007 (a). Time series of $z / L$ ( $L=$ Obuhkov length, $z=$ instrument height) at Sonic 1 (S1), located $4 \mathrm{~m}$ above ground and Sonic 2 (S2), at $2 \mathrm{~m}$ above (b). Note that different symbols are used for positive and negative $z / L$ indicating statically stable and statically unstable. Air temperature (TA), snow surface temperature (TSS) and wind velocity (vw) measured at the weather station are also shown (c) for the same time period. Note that atmospheric stability is enabled for SNOWPACK runs. Data marked by situations 1 and 2 are illustrated in Fig. 11

In Fig. 11 we schematically sketch the temperature profiles and sensible heat fluxes for situations in the morning following the constant flux layer assumption as used in the model and the measured non-constant flux layer. In the mornings, air temperatures were continuously higher than snow surface temperatures (Fig. 9c, Fig. 10c). Consequently, continuously stable conditions for the layer between the snow surface and the measurement height could be assumed. The additional flux measurements, however, indicate unstable conditions at both sensors (S1 and S2) for most situations in the morning (Fig. 9b and Fig. 10b). These observations suggest that there must be a local temperature maximum below $2 \mathrm{~m}$ for these situations (Fig. 11, situation 1). For some hours, measurements even showed a flux directed downwards at $\mathrm{S} 1$ (stable), but upwards at S2 (unstable) (Fig. 9a, b and Fig. 11). Thus, the local air temperature maximum was between 2 and $4 \mathrm{~m}$ (Fig. 11, situation 2). This strong temporal flux divergence in the first four meters above ground is a clear sign for the existence of a stable internal boundary layer. We believe that the advection of a sheet of warm air in the morning caused this temporal change of the depth of the stable internal boundary layer.

We finally compare the measured turbulent fluxes at two instrument heights with the sensible heat flux modeled at the snow surface. The comparison between modeled and measured turbulent fluxes indicate significant differences in the amount of the turbulent heat flux directed towards the snow surface, especially for peak flux situations. The model strongly overestimates the positive sensible heat flux at the snow surface. In the model, the heat flux is driven by strong temperature gradients between the melting snow surface and the air at $4 \mathrm{~m}$ above ground. High wind velocities usually observed in the afternoon further enhance the modeled positive heat flux. For most situations in the morning, the constant flux layer assumption of the model led to a wrong estimation of the atmospheric stability at higher levels $(2-4 \mathrm{~m})$. For these situations the model assumed the whole layer to be stably stratified up to $4 \mathrm{~m}$ (Fig. 11), although measurements showed that the height of stable internal boundary layer was below $2 \mathrm{~m}$. Consequently, the model strongly overestimated the sensible heat flux directed towards the snow cover (Fig. 9a and Fig. 11).

Over a continuous winter snow cover the correction for stability is known to create a shutdown of turbulent fluxes, where very often a strong temperature gradient between the cold surface and the warmer air causes modeled turbulent fluxes strongly underestimating measured fluxes (Stössel et al., 2010). In spring, the existence of a patchy snow cover appears to change this model behavior. In face of high air temperature and high wind velocities the amount of measured 

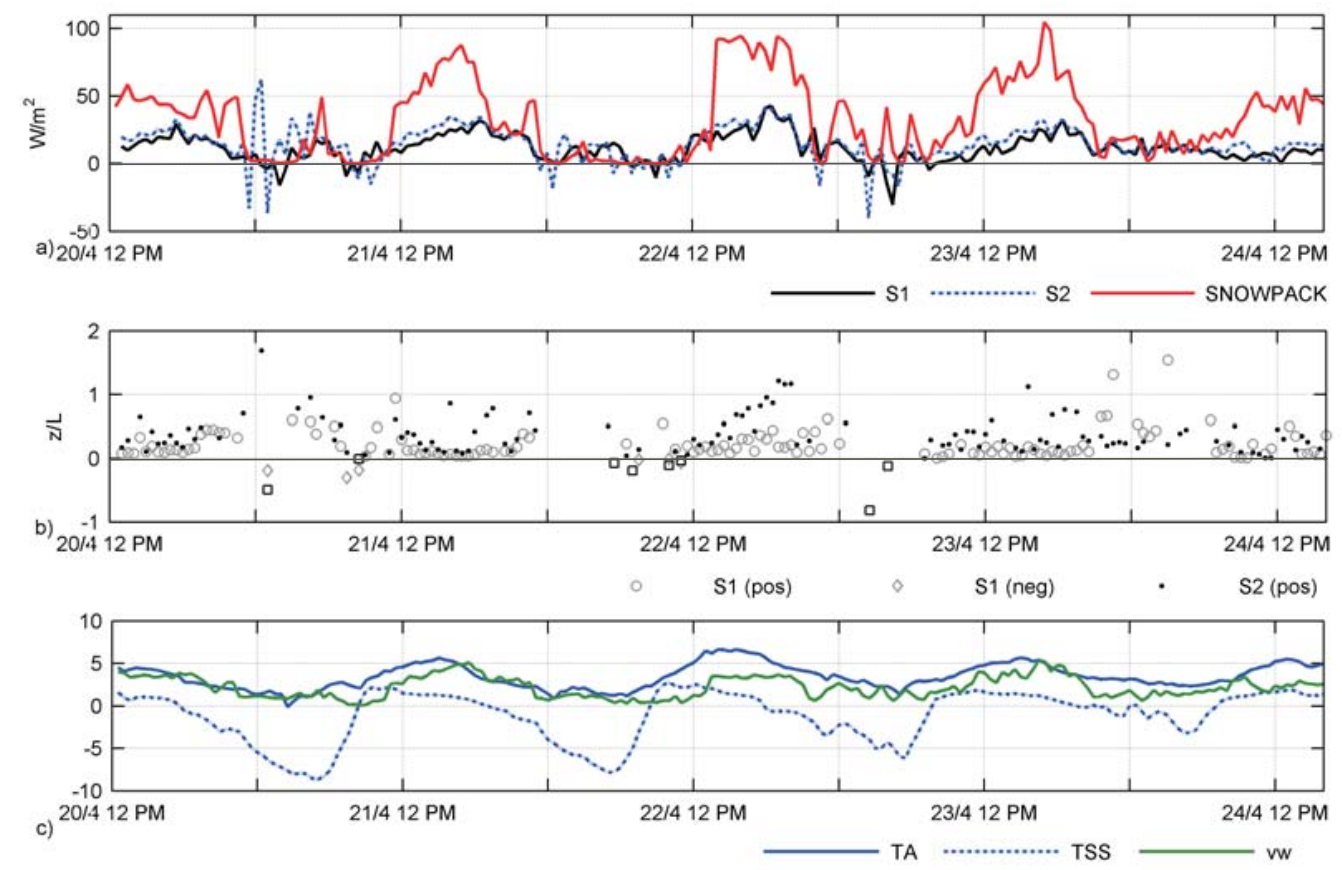

Fig. 10. Time series of measured turbulent heat fluxes $\left(Q_{\mathrm{S}}\right)$ at Sonic 1 (S1) and Sonic 2 (S2), and modeled heat fluxes (SNOWPACK) for time period 20-24 April 2007 (a). Time series of $z / L$ ( $L=$ Obukhov length, $z=$ instrument height) at Sonic 1 (S1), located $4 \mathrm{~m}$ above ground and Sonic 2 (S2), at $2 \mathrm{~m}$ above (b). Note that different symbols are used for positive and negative $z / L$ indicating statically stable and statically unstable. Air temperature (TA), snow surface temperature (TSS) and wind velocity (vw) measured at the weather station are also shown (c) for the same time period. Note that atmospheric stability is enabled for SNOWPACK runs.

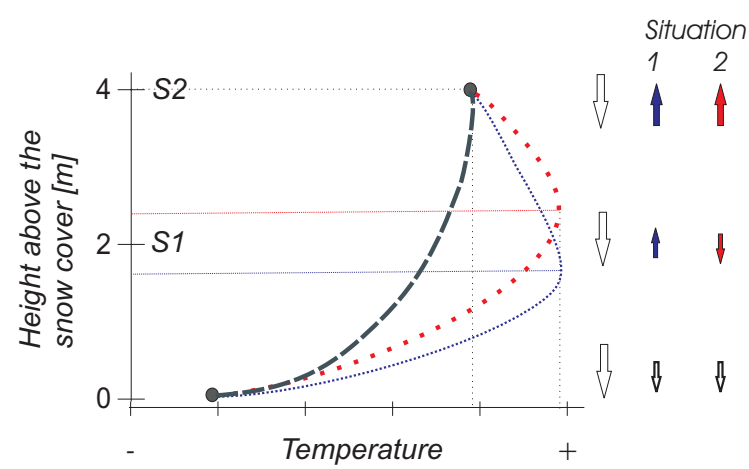

Temperature profile :

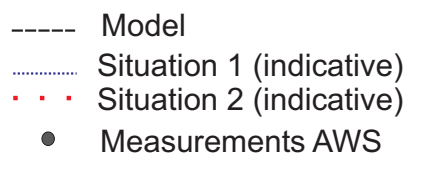

Sensible heat flux $\left[\mathrm{W} / \mathrm{m}^{2}\right]$ :

$\checkmark 40-50$ \& $20-40$ \& $0-20$

$\Rightarrow$ Modelled

$\Rightarrow$ indicative

$\rightarrow$ measured

Fig. 11. Schematic sketch of temperature profile and sensible heat fluxes following constant flux layer assumption (model) and measured in the presence of a stable internal boundary layer (SIBL). The sensible heat flux at the snow surface for the non-constant flux layer is only indicative, because no measurement is available at the snow surface. Data belonging to situation 1 and 2 are marked in Fig. 9. negative turbulent heat flux is small compared to the modeled flux. In the context of increased static stability $(z / L)$ and relatively small observed turbulent heat fluxes towards the ground as well as temporally observed flux divergence in the first $4 \mathrm{~m}$ above ground, the measurements indicate the existence of a stable internal boundary layer (SIBL) close to the snow surface. The SIBL leads to a suppression of turbulence close to the ground.

Using Monin-Obukhov similarity theory (see Eq. 2-4), most models approximate the surface layer to be a constant flux layer (Stull, 1988). Accordingly, models do not account for a SIBL within the atmospheric surface layer. Hence, models tend to strongly overestimate the sensible heat flux transported towards a melting snow surface. Although measured turbulence data suggest a SIBL near the ground, more turbulence measurements close to the ground are required to provide a clear evidence of the development of a SIBL above melting snow, the height of such internal boundary layers and the net amount of sensible heat flux gained at the snow surface. The constant flux layer assumption, however, appears to be inaccurate for simulating turbulent fluxes above melting and patchy snow surfaces in complex terrain.

\section{Conclusions}

We have explored the main micro-meteorological processes driving the spatio-temporal snow ablation dynamics in a 
small Alpine catchment. Based on model results and high resolution measurements we were able to identify ablation patterns controlled by net radiation and net turbulent exchange of sensible and latent heat. Results further confirm earlier results (Grünewald et al., 2010; Egli et al., 2011) on the significant impact of end-of winter snow depth distribution on the patchiness of the melting snow cover. The smallscale information of the snow depth distribution at the end of winter was therefore shown to be essential to accurately model snow ablation dynamics in complex terrain. Furthermore the investigation emphasized the importance of the spatial distribution of wind velocity as a driving factor for the local energy balance and for the snow depth distribution. The effect of the local wind field on the magnitude of turbulent heat fluxes at wind-exposed or wind-sheltered areas pointed to a necessity to drive the energy balance model with meteorological wind fields.

On the very small scale $(\mathrm{m})$, the local advection of sensible heat from adjacent bare ground to snow covered areas was observed to cause strongly increased ablation rates at the upwind edges of snow patches. While for conditions with moderate wind velocities, the significant advection effect appeared to be active over a rather short distance of a few meters, for high wind velocities the advection effect could be observed for a distance of about $20 \mathrm{~m}$. Thus, to capture this effect in energy balance models, a very high horizontal resolution is required. Neglecting the local advection of sensible heat, model results demonstrate that snow ablation is mainly controlled by net radiation fluxes. In some wind-exposed areas, however, net turbulent exchange of sensible and latent heat contributes up to $50 \%$ of the net melt energy. More important is the effect of a SIBL over snow patches. Based on the constant flux layer assumption, energy balance models tend to overestimate snow ablation later in the ablation season due to the fact that most energy balance models do not consider the existence of stable internal boundary layers. The development of a SIBL close to the snow-covered ground significantly alters the local energy balance above melting snow by suppressing turbulence, hence reducing snow ablation. Measured turbulent fluxes above a melting snow cover support this hypothesis by giving evidence of the existence of a SIBL and relatively small turbulent fluxes of sensible heat compared to modeled results.

For a more quantitative investigation of the effect of existing SIBLs on snow ablation a more detailed analysis of turbulent flux profiles above melting snow patches coupled to high-resolution snow ablation measurements is required. Furthermore, considering the locally strong effect of the advection of sensible heat, a consequent next step would be the implementation of advection processes in very highresolution energy balance models on a scale of less than $5 \mathrm{~m}$, by following e.g. the idea of a boundary layer integration method provided by Essery et al. (2006). This approach, however, needs to be augmented by the counteractive effect of SIBL development close to the melting snow surface. One alternative straightforward approach investigating boundary layer dynamics above a patchy melting snow cover would be to use a numerical atmospheric boundary-layer model. Using existing snow-coverage data measured by TLS and ALS may allow us to model the daily development of stable and unstable internal boundary layers as well as their interaction above the heterogeneous surface. This would, however, require a model resolution of approximately $2 \mathrm{~m}$, so that the advection process is resolved (Fig. 3). This is not possible with state of the art meteorological models. Furthermore atmospheric boundary-layer models are computationally expensive and often suffer from insufficient representation of the small-scale land surface characteristics.

Acknowledgements. The wind simulations were made using the Advanced Regional Prediction System (ARPS) developed by the Center for Analysis and Prediction of Storms (CAPS), University of Oklahoma. Part of the work was funded by the Swiss National Science Foundation, the European Community (FP7 project HYDROSYS) and the Center for Environment and Sustainability CCES (SwissEx). We are grateful to our colleagues who helped during the field campaigns, especially Franziska Stössel. We thank the two referees M. Kuhn and S. Dery, as well as the editor M. Van den Broeke for their valuable comments.

Edited by: M. Van den Broeke

\section{References}

Anderton, S. P., White, S. M., and Alvera, B.: Evaluation of spatial variability in snow water equivalent for a high mountain catchment, Hydrol. Process., 18, 435-453, doi:10.1002/hyp.1319, 2004.

Bartelt, P. and Lehning, M.: A physical SNOWPACK model for Avalanche Warning Services, Pt. I: numerical model, Cold Reg. Sci. Technol., 35, 123-145, 2002.

Bavay, M., Lehning, M., Jonas, T., and Löwe, H.: Simulation of future snow cover and discharge in Alpine headwater catchments, Hydrol. Process., 23, 95-108, 2009.

Bellaire, S. and Schweizer, J.: Measuring spatial variations of weak layer and slab properties with regard to snow slope stability, Cold Reg. Sci. Technol., 65, 234-241, doi:10.1016/j.coldregions.2010.08.013, 2011.

Bewley, D., Essery, R., Pomeroy, J., and Ménard, C.: Measurements and modelling of snowmelt and turbulent heat fluxes over shrub tundra, Hydrol. Earth Syst. Sci., 14, 1331-1340, doi:10.5194/hess-14-1331-2010, 2010.

Blöschl, G.: Scaling issues in snow hydrology, Hydrol. Process., 13, 2149-2175, 1999.

Calanca, P.: A note on the roughness length for temperature over melting snow and ice, Q. J. R. Meteorol. Soc., 127, 255-260, 2001.

Clark, M. P., Hendrikx, J., Slater, A. G., Kavetski, D., Anderson, B., Cullen, N. J., Kerr, T., Örn Hreinsson, E., Woods, R. A.: Representing spatial variability of snow water equivalent in hydrologic and land-surface models: A review, Water Resour. Res., 47, W07539, doi:10.1029/2011WR010745, 2011. 
Clifton, A. and Lehning, M.: Improvement and validation of a snow saltation model using wind tunnel measurements, Earth Surf. Proc. Land., 33, 2156-2173, 2008.

Cline, D. W.: Snow surface energy exchanges and snowmelt at a continental, midlatitude Alpine site, Water Resour. Res., 33, 689-701, doi:10.1029/97WR00026, 1997.

Dadic, R., Mott, R., Lehning, M., and Burlando, P.: Wind Influence on Snow Depth Distribution and Accumulation over Glaciers, J. Geophys. Res., 115, F01012, doi:10.1029/2009JF001261, 2010.

Dickinson, W. T. and Whiteley, H. R.: A sampling scheme for shallow snow packs, Bulletin of the International Association of Hydrological Sciences, 16, 247-258, 1972.

Doorschot, J., Lehning, M., and Vrouwe, A.: Field measurements of snow drift threshold and mass fluxes, and related model simulations, Bound.-Lay. Meteorol., 113, 347-368, 2004.

Egli, L., Jonas, T., Grünewald, T., Schirmer, M., and Burlando, P.: Dynamics of snow ablation in a small Alpine catchment observed by repeated terrestrial laser scans, Hydrol. Process., doi:10.1002/hyp.8244, 2011.

Essery, R.: Modelling fluxes of momentum, sensible heat and latent heat over heterogeneous snowcover, Q. J. roy. meteor. soc., 123, 1867-1883, 1997.

Essery, R., Granger, R., and Pomeroy, J. W.: Boundary-layer growth and advection of heat over snow and soil patches: modelling and parameterization, Hydrol. Process., 20, 953-967, 2006.

Fierz, C. and Lehning, M.: Assessment of the microstructure-based snow-cover model SNOWPACK: thermal and mechanical properties, Cold Reg. Sci. Technol., 33, 123-131, 2001.

Fujita, K., Hiyama, K., Iida, H., and Ageta, Y.: Self-regulated fluctuations in the ablation of a snow patch over four decades, Water Resour. Res., 46, W11541, doi:10:1029/2009WR008383, 2010.

Granger, R. J., Pomeroy, J. W., and Parvianen, J.: Boundary layer integration approach to advection of sensible heat to a patchy snowcover, Hydrol. Process., 16, 3559-3569, 2002.

Granger, R. J., Pomeroy, J. W., and Essery, R.: Boundary-layer growth and advection of heat over snow and soil patches: field observations, Hydrol. Process., 20, 953-967, 2006.

Groot Zwaaftink, C. D., Löwe, H., Mott, R., Bavay, M., and Lehning, M..: Drifting snow sublimation: a high resolution 3D model with temperature and moisture feedbacks, J. Geophys. Res., 116, D16107, doi:10.1029/2011JD015754, 2011.

Grünewald, T., Schirmer, M., Mott, R., and Lehning, M.: Spatial and temporal variability of snow depth and ablation rates in a small mountain catchment, The Cryosphere, 4, 215-225, doi:10.5194/tc-4-215-2010, 2010. .

Grünewald, T. and Lehning, M.: Altitudinal dependency of snow amounts in two small alpine catchments: can catchment-wide snow amounts be estimated via single snow or precipitation stations?, Ann. Glaiol., 52, 153-158, 2011.

Helbig, N., Löwe, H., and Lehning, M: Radiosity approach for the shortwave surface radiation balance in complex terrain, J. Atmos. Sci., 66, 2900-2912, 2009.

Helbig, N., Lehning, M., Löwe, H., and Mayer, B.: Explicit validation of a shortwave radiation model over snow covered complex terrain, J. Geophys. Res., 115, D18113, doi:10.1029/2010JD013970, 2010.

Jonas, T., Marty, C., and Magnusson, J.: Estimating the snow water equivalent from snow depth measurements in the Swiss Alps, J. Hydrol., 378, 161-167, 2009.
Lehning, M. and Fierz, C.: Assessment of snow transport in avalanche terrain, Cold Reg. Sci. Technol., 51, 240-252, doi:10.1016/j.coldregions.2007.05.012, 2008.

Lehning, M., Bartelt, P., Brown, B., and Fierz, C.: A physical SNOWPACK model for the Swiss avalanche warning: Part III: meteorological forcing, thin layer formation and evaluation, Cold Reg. Sci. and Technol., 35, 169-184, doi:10.1016/S0165232X(02)00072-1, 2002.

Lehning, M., Völksch, I., Gustafsson, D., Nguyen, T. A., Stähli, M., and Zappa, M.: A detailed model of mountain surface processes and its application to snow hydrology, Hydrol. Process., 20, 2111-2128, 2006.

Lehning, M., Löwe, H., Ryser, M., and Raderschall, N.: Inhomogeneous precipitation distribution and snow transport in steep terrain, Water Resour. Res., 44. W09425, doi:10.1029/2007WR006544, 2008.

Liston, G. E.: Local Advection of momentum, heat and moisture during the melt of patchy snow covers, J. Appl. Meteorol., 34, 1705-1715, 1995.

Liston, G. E. and Sturm, M.: Winter precipitation patternsin arctic Alaska determined from a blowing-snow model and snow-depth observations, J. Hydromet., 3, 646-659, 2002.

Liston, G. E., Haehnel, R. B., Sturm, M., Hiemstra, C. A., Berezovskaya, S., and Tabler, R. D.: Instruments and methods simulating complex snow distributions in windy environments using SnowTran-3D, J. Glaciol., 53, 241-256, 2007.

Luce, C. H., Tarboton, D. G., and Cooley K. R.: The influence of the spatial distribution of snow on basin-averaged snowmelt, Hydrol. Process., 12, 1671-1683, 1998.

Male, D. H. and Granger, R. J.: Snow surface energy exchange, Water Resour. Res., 17, 609-627, doi:10.1029/WR017i003p00609, 1981.

Manes, C., Guala, M., Löwe, H., Bartlett, S., Egli, L., and Lehning, M.: Statistical properties of fresh snow roughness, Water Resour. Res., 44, W11407, doi:10.1029/2007WR006689, 2008.

Marks, D., Domingo, J., Susong., D., Link, T., and Garen, D.: A spatially distributed energy balance snowmelt model for application in mountain basins, Hydrol. Process., 13, 1935-1959, 1999.

Marsh, P. and Pomeroy, J. W.: Meltwater fluxes at an arctic foresttundra site, Hydrol. Process, 10, 1383-1400, 1996.

Michlmayr, G., Lehning, M., Kobolotschnig, G., Holzmann, H., Zappa, M., Mott, R., and Schöner, W.: Application of the Alpine 3D model for glacier mass balance and glacier runoff studies at Goldbergkees, Austria, Hydrol. Process., 22, 3941-3949, 2008.

Morris, E. M.: Turbulent fluxes over snow and ice, J. Hydrol., 105, 205-233, 1989.

Mott, R. and Lehning, M.: Meteorological Modelling of very-high resolution wind fields and snow deposition for mountains, J. Hydrometeorol., 11, 934-949, doi:10.1175/2010JHM1216.1, 2010.

Mott, R., Schirmer, M., Bavay, M., Grünewald, T., and Lehning, M.: Understanding snow-transport processes shaping the mountain snow-cover, The Cryosphere, 4, 545-559, doi:10.5194/tc-4-5452010, 2010. Mott, R., Schirmer,

Mott, R., Schirmer, M., and Lehning, M.: Scaling properties of wind and snow depth distribution in an Alpine catchment, J. Geophys. Res., 116, D06106, doi:10.1029/2010JD014886, 2011.

Pohl, S. and Marsh, P.: Modelling the spatial-temporal variability of spring snowmelt in an arctic catchment, Hydrol. Process., 20, 1773-1792. doi:10.1002/hyp.5955, 2006. 
Pohl, S., Marsh, P., and Liston, G. E.: Spatial-temporal variability in turbulent fluxes during spring snowmelt, Arct. Antarct. Alp. Res., 38, 136-146, 2006.

Pomeroy, J. W. and Gray, D. M.: Snowcover: Accumulation, Redistribution and Management, National Hydrology Research Institute Science Report No. 7., Saskatoon, Saskatchewan, Canada, 144 pp., 1995.

Pomeroy, J. W., Gray, D. M., Shook, K. R., Toth, B., Essery, R. L. H., Pietroniro, A., and Hedstrom, N.: An evaluation of snow accumulation and ablation processes for land surface modelling, Hydrol. Process., 12, 2339-2367, 1998.

Prokop, A., Schirmer, M., Rub, M., Lehning, M., and Stocker, M.: A comparison of measurement methods: Terrestrial laser scanning, tachymetry and snow probing, for the determination of spatial snow depth distribution on slopes, Ann. Glaciol., 49, 210216, 2008.

Prokop, A.: Assessing the applicability of terrestrial laser scanning for spatial snow depth measurements, Cold Reg. Sci. Technol., 54, 155-163, 2008.

Raderschall, N., Lehning, M., and Schär, M.: Fine-scale modeling of the boundary layer wind field over steep topography, Water Resour. Res., 44, W09425, doi:10.1029/2007WR006544, 2008.

Schaffhauser, A., Adams, M., Fromm, R., Jörg, P., Luzi, G., Noferini, L., and Sailer, R.: Remote sensing based retrieval of snow-cover properties, Cold Reg. Sci. Technol., 54, 164-175, 2008 .
Schirmer, M., Wirz, V., Clifton, A., and Lehning, M.: Persistence in intra-annual snow depth distribution: 1. Measurements and topographic control, Water Resour. Res., 47, W09516, doi:10.1029/2010WR009426, 2011.

Shook, K., Gray, D. M., and Pomeroy, J. W.: Temporal variation in snowcover area during melt in prairie and alpine environments, Nord. Hydrol., 24, 183-198, 1993.

Shook, K.: Simulation of ablation of prairie snowcovers, Ph.D thesis, University of Saskatchewan, 189 pp., 1995.

Stearns, C. and Weidner, G.: Sensible and latent heat estimates in Antarctica. Antar. res. s., 61, 109-138, 1994.

Stössel, F., Manes, C., Guala, M., Fierz, C., and Lehning, M.: Micrometeorological and morphological observations of surface hoar dynamics on a mountain snow-cover, Water Resour. Res., 46, W04511, doi:10.1029/2009WR008198, 2010.

Stull, R.: Boundary Layer Meteorology. Kluwer Academic, 666 pp., 1988.

Takahara, H. and Higuchi, K.: Thermal modification of air moving over melting snow surfaces, Ann. Glaciol., 6, 235-237, 1985.

Xue, M., Droegemeier, K. K., Wong, V., Shapiro, A., and Brewster, K.: The Advanced Regional Prediction System (ARPS) - A multi-scale non-hydrostatic atmospheric simulation model. Part II: model physics and applications, Meteorol. Atmos. Phys., 76, 143-165, 2004. 